\title{
High Survivorship and Few Complications With Cementless Total Wrist Arthroplasty at a Mean Followup of 9 Years
}

\author{
Joseph A. Gil MD, Robin N. Kamal MD, Eugene Cone MD, \\ Arnold-Peter C. Weiss MD
}

Received: 11 April 2017/Accepted: 7 July 2017/Published online: 18 July 2017

(C) The Association of Bone and Joint Surgeons(B) 2017

\begin{abstract}
Background Total wrist arthroplasty (TWA) has been described as traditionally being performed with fixation in the radius and carpus with cement. The TWA implant used in our series has been associated with promising results in studies with up to 6 years followup; however, studies evaluating survivorship, pain, and function with this implant are limited.

Question/Purpose (1) To report ROM and pain scores after wrist reconstruction with cementless fourth-generation TWA at a mean followup of 9 years (range, 4.8-14.7

Each author certifies that neither he or she, nor any member of his or her immediate family, have funding or commercial associations (consultancies, stock ownership, equity interest, patent/licensing arrangements, etc) that might pose a conflict of interest in connection with the submitted article.

All ICMJE Conflict of Interest Forms for authors and Clinical Orthopaedics and Related Research ${ }^{(\mathbb{R}}$ editors and board members are on file with the publication and can be viewed on request.

Clinical Orthopaedics and Related Research ${ }^{\mathbb{R}}$ neither advocates nor endorses the use of any treatment, drug, or device. Readers are encouraged to always seek additional information, including FDAapproval status, of any drug or device prior to clinical use. Lifespan IRB approved the human protocol for this investigation, and each author certifies that all investigations were conducted in conformity with ethical principles of research.

This work was performed at the Department of Orthopaedics, Warren Alpert Medical School of Brown University, Rhode Island Hospital, Providence, RI, USA.
\end{abstract}

J. A. Gil, A.-P. C. Weiss

Department of Orthopaedics, Warren Alpert Medical School of

Brown University, Rhode Island Hospital, Providence, RI, USA

R. N. Kamal

Department of Orthopaedic Surgery, Stanford University Medical Center, Hand and Upper Extremity Clinic, Redwood City, CA, USA years). (2) To report complications of a cementless fourthgeneration TWA and the cumulative probability of not undergoing a revision at a mean followup of 9 years.

Methods This is a retrospective case series of 69 patients who were treated for pancarpal wrist arthritis between 2002 and 2014. Of those, 31 had inflammatory arthritis (rheumatoid arthritis [ $\mathrm{n}=29$ ], juvenile rheumatoid arthritis [n $=1]$, and psoriatic arthritis $[\mathrm{n}=1]$ ); all of these patients received TWA with the cementless implant studied in this investigation. Another 38 patients had osteoarthritis or posttraumatic arthritis; in this subgroup, 28 patients were 65 years or younger, and all underwent wrist fusion (none were offered TWA). Ten patients with osteoarthritis were older than 65 years and all were offered TWA; of those, eight underwent TWA, and two declined the procedure and instead preferred and underwent total wrist arthrodesis. The mean age of the 39 patients who had TWA was $56 \pm 8.9$ years (range, 31-78 years) at the time of surgery; 36 were women and three were men. The patients who underwent TWA were seen at a minimum of 4 years (mean, 9 years; range, 4-15 years), and all had been examined in 2016 as part of this study except for one patient who died 9 years after surgery. The dominant wrist was involved in $60 \%$ (25) of the patients. All patients were immobilized for 4 weeks postoperatively and then underwent hand therapy for 4 to 6 weeks. Pain and ROM were gathered before surgery as part of clinical care, and were measured again at latest

\section{E. Cone}

Division of Urology, Department of Surgery, Duke University School of Medicine, Durham, NC, USA

A.-P. C. Weiss ( $\square)$

University Orthopedics, Inc, 2 Dudley Street, Suite 200,

Providence, RI 02905, USA

e-mail: apcweiss@brown.edu 
followup; at latest followup, radiographs were analyzed (by the senior author) for evidence of loosening, defined as any implant migration compared with any previous radiograph with evidence of periimplant osteolysis and bone resorption. Subjective pain score was assessed by a verbal pain scale $(0-10)$ and ROM was measured with a goniometer. Complications were determined by chart review and final examination. Kaplan Meier survival analysis was performed to estimate the cumulative probability of not undergoing a revision.

Results The mean preoperative active ROM was $34^{\circ} \pm$ $18^{\circ}$ flexion and $36^{\circ} \pm 18^{\circ}$ extension. Postoperatively, the mean active ROM was $37^{\circ} \pm 14^{\circ}$ flexion and $29^{\circ} \pm 13^{\circ}$ extension. The mean difference between the preoperative pain score $(8.6 \pm 1.2)$ and postoperative pain score $(0.4 \pm$ $0.8)$ was $8.1 \pm 1.9(\mathrm{p}<0.001)$. Implant loosening occurred in three $(7.7 \%)$ patients. No other complications occurred in this series. Kaplan-Meier survivorship analysis estimated the cumulative probability of remaining free from revision as $78 \%(95 \% \mathrm{CI}, 62 \%-91 \%)$ at 15 years.

Conclusion Cementless fourth-generation TWA improves pain while generally preserving the preoperative arc of motion. The cumulative probability of remaining free from revision at 14.7 years after the index procedure is 77.7\% (95\% CI, 62.0\%-91.4\%). Future studies should compare alternative approaches for patients with endstage wrist arthritis; such evaluations-which might compare TWA implants, or TWAs with arthrodesis-will almost certainly need to be multicenter, as the problem is relatively uncommon.

Level of Evidence Level IV, therapeutic study.

\section{Introduction}

Despite the relatively dependable results of total wrist arthrodesis, the functional advantage of preserving motion with total wrist arthroplasty (TWA) has motivated efforts to refine implant design and investigate outcomes of TWA in the treatment of wrist arthritis [4, 5, 15, 24]. Unlike total wrist arthrodesis, which has been shown to make it difficult to complete certain activities of daily living, TWA allows for preservation of some wrist motion [15, 23]. A prior systematic review showed that complication rates of total wrist arthrodesis averaged $17 \%$ [7]. In a retrospective study of 22 patients who had been treated with wrist arthrodesis, $20(91 \%)$ said they would have another procedure performed if it meant that they could move their wrist again, with patients reporting substantial dysfunction after arthrodesis [2]. A cost-utility study showed that TWA was as effective as arthrodesis with only a small incremental cost [8]. Despite there not being a prospective randomized controlled trial comparing TWA with total wrist arthrodesis, many patients prefer TWA over wrist arthrodesis $[11,18]$.

Total wrist implant designs and their insertion techniques have evolved during the past 30 years. As reported by Weiss et al. [24], the one-piece silicone elastomer implant design first popularized by Swanson in the 1970s, has evolved into third-generation implants consisting of separate radial and carpal base components with an interposed polyethylene component [7, 13, 14, 17, 22, 24, 25]. The fourth-generation TWA used in our series is part of a small group of implant designs redesigned to enhance articulation between the radial and polyethylene components while incorporating the carpal screw fixation and porous coated radial component elements of the thirdgeneration designs, with promising results in two prior reports with mid-term followup [10, 25].

The aims of the current study were to: (1) report ROM and pain scores after wrist reconstruction with a cementless fourth-generation TWA at a mean followup of 9 years (range, 5-15 years); (2) report complications of the cementless fourth-generation TWA and the cumulative probability of not undergoing a revision at a mean followup of 9 years.

\section{Patients and Methods}

Between 2002 and 2014, one surgeon (APCW) treated 69 patients surgically for pancarpal wrist arthritis that inhibited them from completing activities of daily living owing to substantial pain (Fig. 1). Of those, 31 had inflammatory arthritis and 38 had degenerative or posttraumatic arthritis. All 31 patients with inflammatory arthritis were offered and received a TWA; there was no minimum age for a TWA in this subgroup. Among the group with degenerative or posttraumatic arthritis, 28 patients were 65 years or younger, and all underwent wrist fusion; this group of patients was not offered a TWA. Ten patients in the degenerative or posttraumatic arthritis group were older than 65 years; of those, eight underwent TWA and two declined TWA and underwent total wrist arthrodesis. The treatment rationale was to use TWA in only older and theoretically less-active patients with osteoarthritis or posttraumatic arthritis (with the arbitrary cutoff age set at 65 years) since TWA traditionally had not been used in this subgroup, therefore data regarding survival were sparse [6].

All patients who underwent TWA had adequate bone stock to accommodate a TWA. In all of these patients, an uncemented, press fit impaction technique was used. Although the use of TWA in the USA is approved for use with cement only, some surgeons (including our group) prefer to implant the prosthesis without cement because of 


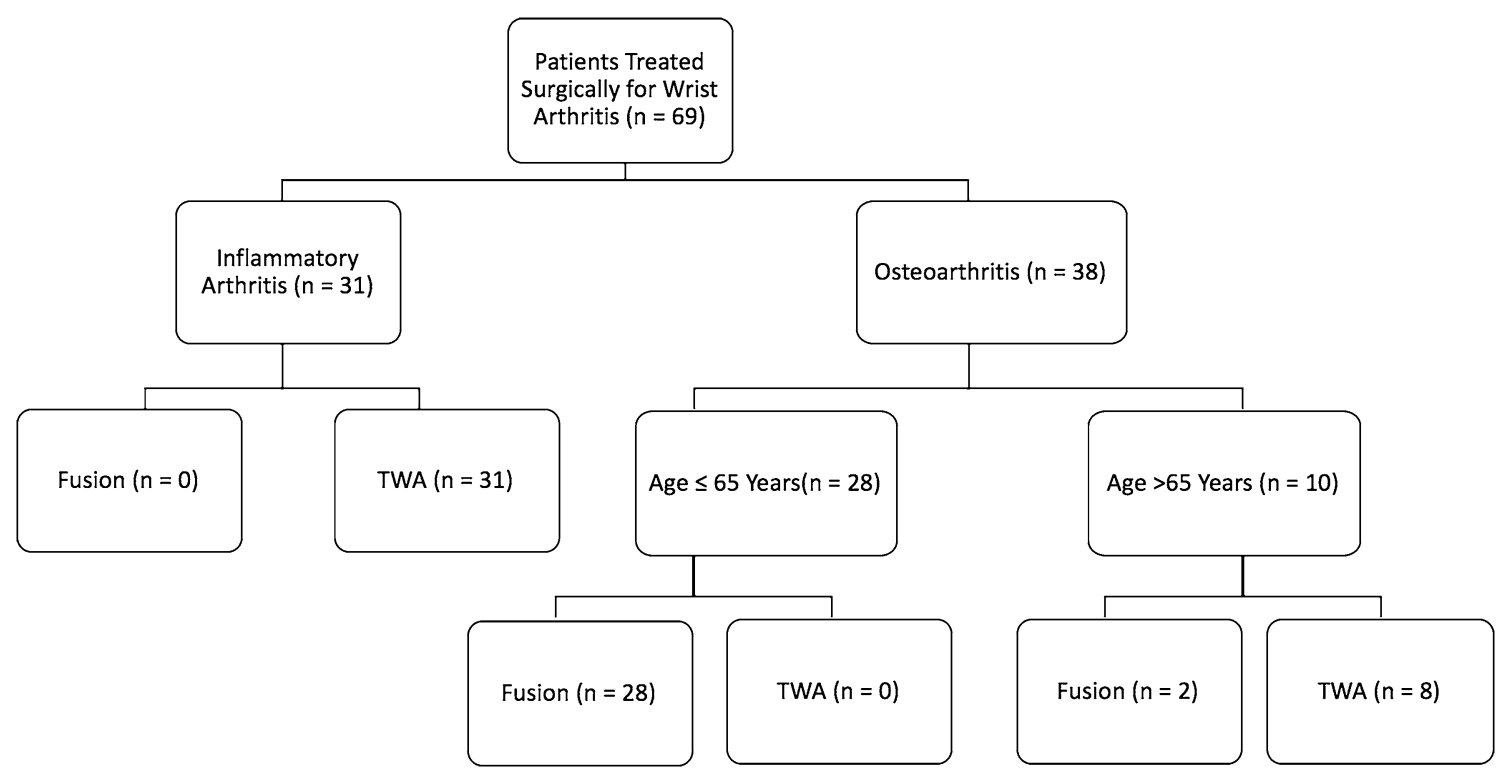

Fig. 1 Between 2002 and 2014, 69 patients were surgically treated for wrist arthritis that inhibited them from completing activities of daily living. All 69 patients were last examined in 2016 except for one

the advantage of stability achieved through osseous integration, maintenance of bone stock, and theoretical longevity $[1,16]$. The 39 patients who underwent TWA were seen at a minimum of 4 years (mean, 9 years; range, 5-15 years), and all patients were seen in 2016 as part of this study except for one patient who died 9 years after surgery and 2 months after a routine followup. After obtaining approval from our institutional review board, the charts of all patients who underwent TWA with an uncemented TWA implant were retrospectively evaluated.

Pain and ROM were gathered before surgery as part of clinical care, and were measured again at latest followup for this study by the senior author (A-PCW). Subjective pain was assessed by a verbal pain scale (0-10) and ROM was measured with a goniometer by the senior author (APCW). Complications were determined by chart review and final followup. Kaplan Meier survival analysis was performed with SPSS Version 24.0 (IBM Corporation, Armonk, NY, USA) to estimate the cumulative probability of not undergoing a revision. Age, hand dominance, ROM, and indication for TWA were recorded. Radiographs were analyzed by the senior author (A-PCW); radiographic loosening was defined as any implant migration compared with any previous radiograph with evidence of periimplant osteolysis and bone resorption.

The TWA implant used in this series was a Universal2 ${ }^{\mathrm{TM}}$ (Integra LifeSciences Corporation, Plainsboro, NJ, USA), which is a fourth-generation design with an ellipsoid articulation [21]. The redesign of its predecessor to the ellipsoid design was based on a finite element model patient who died 9.1 years after surgery. This patient was seen for the 9-year followup. TWA $=$ total wrist arthroplasty.

analysis which indicated greater contact area, lower peak contact pressures, and greater stability [13]. The implant has a central carpal stem and areas for two-screw fixation to the carpus and a radial component that is porous coated to promote osseous integration.

\section{Surgical Technique}

A surgical technique similar to that originally described by Menon [19] was used for all 39 patients. Thirty-six patients had a Darrach procedure [12] completed first, and then the radius was broached and a trial radial implant was placed before the carpus was addressed. After excising the lunate, a drill hole was made through the capitate, using the third metacarpal as a guide, and the carpal cutting jig was placed. After carpal cuts were made, a trial carpal component and polyethylene were placed. The wrist then was tested for stability during passive flexion and extension with polyethylene carpal inserts of differing sizes until appropriate stability was achieved. Because of the importance of attaining carpal fusion to aid carpal component fixation, additional bone graft from the excised carpal bones was placed in the cartilage denuded intercarpal joints (specifically the remaining distal scaphoid-capitate, hamate-capitate and hamate-distal triquetral joints) before final placement of the carpal component. Carpal and radial components were placed in a press fit fashion without cement use. All patients wore a short arm splint for 1 week, followed by a short arm cast for 3 weeks, and then 
underwent 4 to 6 weeks of hand therapy. Patients were allowed full use at 6 weeks, however they were instructed to avoid lifting greater than 10 pounds with the implanted extremity, on a long-term basis.

\section{Results}

Active flexion and extension mean was $37^{\circ}$ flexion (SD, \pm $14^{\circ}$ ) and $29^{\circ}$ extension $\left(\mathrm{SD}, \pm 13^{\circ}\right)$. The mean difference between the preoperative pain score $(8.6 \pm 1.2)$ and postoperative pain score $(0.4 \pm 0.8)$ was $8.1 \pm 1.9(\mathrm{p}<0.001)$. Complications included osteolysis with implant loosening in three $(7.7 \%)$ patients, with two undergoing surgical revision with an uncemented carpal component and one with revision of the carpal and radial components (Fig. 1). There were no other complications (such as infection, fractures, or excessive stiffness) in this series. KaplanMeier survivorship analysis estimated that the cumulative probability of remaining free from revision was $78 \%(95 \%$ CI, 62\%-91\%) at 15 years (Fig. 2).

\section{Discussion}

Total wrist implant designs and surgical techniques have evolved during the past 30 years $[15,26]$. Previous studies have shown the outcomes and survivorship of the cementless fourth-generation TWA used in the current series up to a mean of 6 years of followup [3, 9, 20]. Results of these studies appeared similar to ours regarding motion (Table 1). Our study, with a mean 9-year followup of a cementless fourth-generation implant, found that TWA improves pain while generally preserving the preoperative arc of motion. The cumulative probability of remaining free from revision at 14.8 years followup is $77.7 \%(95 \%$ CI, $62.0 \%-91.4 \%$ ).

This study has numerous limitations. First, the generalizability of the results is limited owing to it being a singlesurgeon series performed in an academic medical center; we have described the indications and the patient population, but caution the reader that other settings using other indications may achieve different results. As a retrospective case series, the study is susceptible to selection bias, particularly with the younger subset (younger than 65 years) of patients who all underwent primary total wrist arthrodesis. In contrast, all patients with inflammatory arthritis underwent a TWA. Therefore, when interpreting the results, it is critical to recognize that they are most relevant to patients with inflammatory arthritis or in patients with degenerative or posttraumatic osteoarthritis who are older than 65 years. Our study is limited given that we did not use any validated patient-reported outcome instruments. Moreover, the outcomes were assessed by the surgeon (APCW) who was directly involved in the care; assessment bias (the lack of validated patient-reported outcomes measurements) and assessor bias (an individual assessing patients whose care he or she was involved in) have a tendency to inflate apparent benefits of treatment in clinical research. Another limitation is that while some of the patients included in the series had more than 10 years followup, others had as little as 4 years; longer surveillance will be important for patients in this group as in any reconstructive series, as loosening may yet occur in some of these patients.

Our cumulative probability of remaining free from revision at 15 years is $78 \%(95 \% \mathrm{CI}, 62 \%-91 \%)$, and we
Fig. 2 The Kaplan Meier survival estimate for the 39 patients included in the examined cohort is shown. TWA = total wrist arthroplasty.

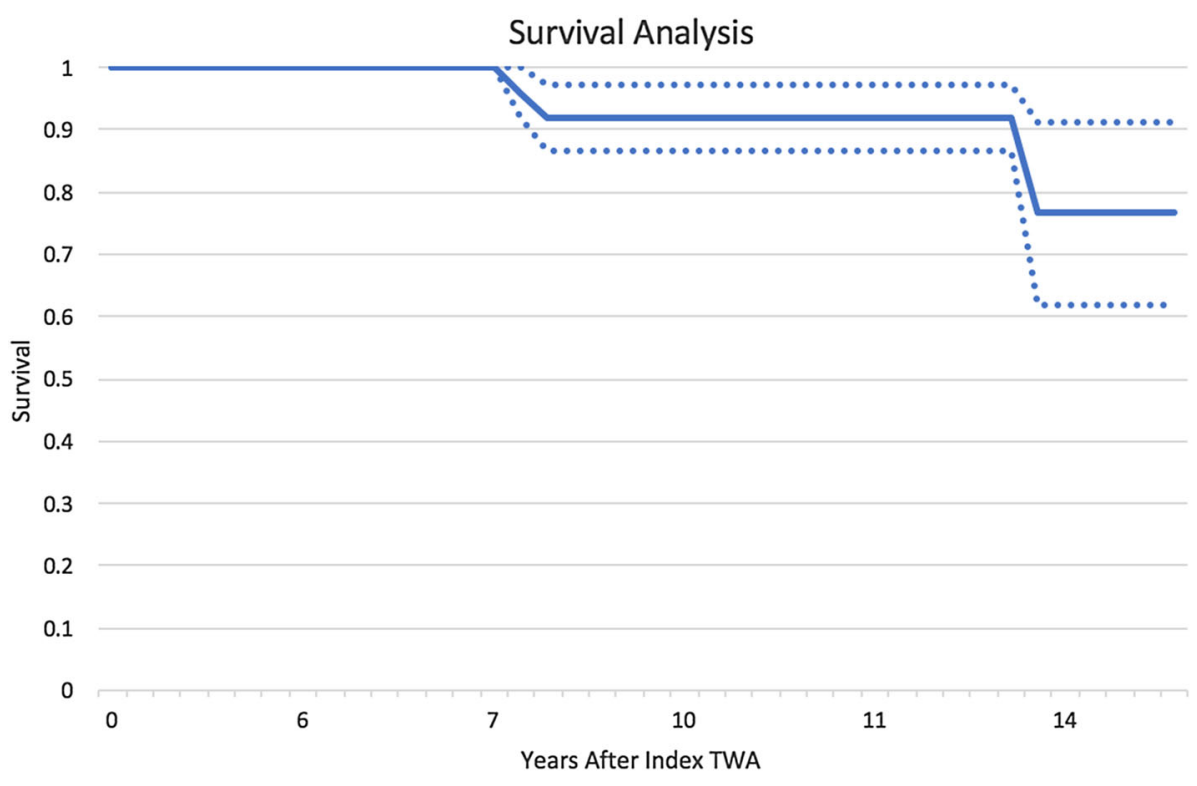


Table 1. Reported outcomes and survivorship using the cementless fourth-generation TWA implant used in the current study

\begin{tabular}{|c|c|c|c|c|c|c|}
\hline Study & Methods & Indications & Mean followup & $\begin{array}{l}\text { Mean flexion- } \\
\text { extension arc }\end{array}$ & Pain (VAS) & $\begin{array}{l}\text { Kaplan-Meier } \\
\text { survivorship } \\
\text { (removal of } \\
\text { components as } \\
\text { endpoint) }\end{array}$ \\
\hline $\begin{array}{l}\text { Cooney et al. } \\
\text { [9] }\end{array}$ & $\begin{array}{l}\text { Retrospective review of } \\
46 \text { TWAs (either } \\
\text { third- or fourth- } \\
\text { generation TWA } \\
\text { system) }\end{array}$ & $\begin{array}{l}36 \text { for rheumatoid arthritis, } \\
10 \text { for posttraumatic } \\
\text { arthritis }\end{array}$ & 6 years & $68^{\circ}$ & $\begin{array}{l}\text { Preoperative, } 7 \\
\text { Postoperative, } 2.3\end{array}$ & Not performed \\
\hline $\begin{array}{l}\text { Morapudi } \\
\text { et al. [20] }\end{array}$ & $\begin{array}{l}\text { Retrospective review of } \\
21 \text { TWAs (same } \\
\text { implant used in our } \\
\text { series) }\end{array}$ & $\begin{array}{l}19 \text { for rheumatoid arthritis, } \\
2 \text { for posttraumatic } \\
\text { arthritis }\end{array}$ & 3.1 years & $53^{\circ}$ & VAS not collected & Not performed \\
\hline $\begin{array}{l}\text { Badge et al. } \\
\text { [3] }\end{array}$ & $\begin{array}{l}\text { Retrospective review of } \\
95 \text { TWAs (same } \\
\text { implant used in our } \\
\text { series) }\end{array}$ & 95 for rheumatoid arthritis & 4.4 years & $50^{\circ}$ & $\begin{array}{l}\text { Preoperative, } 8.1 \\
\text { Postoperative, } 5.4\end{array}$ & $91 \%$ at 7.8 years \\
\hline $\begin{array}{l}\text { Ferreres et al. } \\
\quad[10]\end{array}$ & $\begin{array}{l}\text { Retrospective review of } \\
21 \text { TWAs (same } \\
\text { implant used in our } \\
\text { series) }\end{array}$ & $\begin{array}{l}14 \text { for rheumatoid arthritis, } \\
2 \text { for Kienbocks, } \\
1 \text { for posttraumatic arthritis, } \\
1 \text { for chondrocalcinosis }\end{array}$ & 5.5 years & $68^{\circ}$ & VAS not collected & Not performed \\
\hline
\end{tabular}

observed few complications. Yeoh and Tourret [27] performed a systematic review to examine the outcomes of TWAs performed from 2009 to 2014. Implant survival for TWA in their study, using the same system used in our series, was $100 \%$ at 3 to 5 years followup. Two series that used the implant we evaluated [10, 20] seemed to have a higher proportion of patients reporting complications than we observed (nine of 21 and three of 21 , respectively). The complications they reported included pain, stiffness (arc of ROM $<15^{\circ}$ ), infections, and one dislocation. The only complication we observed was loosening, which occurred in $7.7 \%(n=3)$ of patients. Our results seemed comparable to those of Badge et al. [3] who documented survivorship free from revision at intermediate term; they reported that the probability of survival at 7.8 years was $91 \%(95 \% \mathrm{CI}$, $84 \%-91 \%)$. The confidence intervals they reported overlapped broadly with those in our study, which tends to validate our finding on survivorship. Badge et al. [3] retrospectively examined the clinical and radiologic outcomes of 95 TWAs performed with the same system we used. Their mean followup was 4.4 years (range, 2-10 years), and their reported probability of survival at 7.8 years was $91 \%$ (95\% CI, 84\%-91\%). Reported adverse effects of their patients included persistent pain $(n=9)$, joint stiffness $\left(\operatorname{arc}<15^{\circ}, \mathrm{n}=9\right)$, wound infection $(\mathrm{n}=2)$, and dislocation $(\mathrm{n}=1)$. In contrast to the studies by Badge et al. [3] and Yeoh and Tourret [27], our only complication was loosening, which occurred in $7.7 \%(n=3)$ of patients.

A cementless TWA improves pain while generally preserving the preoperative arc of motion. The cumulative probability of remaining free from revision at 15 years is $78 \%$ (95\% CI, 62\%-91\%). The results of our study, and those of previous investigations that assessed the same system we used [3, 10], suggest that the fourth-generation implant may be more durable, and the TWA has shifted from a surgical option that is controversial to one that is more predictable and reliable for patients with rheumatoid arthritis and posttraumatic osteoarthritis. Our experience and data from the current study have caused us to broaden our current indications in patients with osteoarthritis and posttraumatic arthritis who are younger than 65 years. Future studies are needed to see whether this results in measurable improvements in patient-reported outcomes. In addition, future studies should compare alternative approaches for patients with endstage wrist arthritis; such evaluations-which might compare TWA implants, or TWAs with arthrodesis-will need to be multicenter, as the problem is relatively uncommon.

\section{References}

1. Adams BD. Total wrist arthroplasty. Tech Hand Up Extrem Surg. 2004;8:130-137.

2. Adey L, Ring D, Jupiter JB. Health status after total wrist arthrodesis for posttraumatic arthritis. J Hand Surg Am. 2005;30:932-936.

3. Badge R, Kailash K, Dickson DR, Mahalingam S, Raza A, Birch A, Nuttall D, Murali SR, Hayton MJ, Talwalkar S, Watts AC, Trail IA. Medium-term outcomes of the Universal-2 total wrist arthroplasty in patients with rheumatoid arthritis. Bone Joint $J$. 2016;98:1642-1647. 
4. Boeckstyns ME. Wrist arthroplasty: a systematic review. Dan Med J. 2014;61:A4834.

5. Boeckstyns ME, Herzberg G, Merser S. Favorable results after total wrist arthroplasty: 65 wrists in 60 patients followed for 5-9 years. Acta Orthop. 2013;84:415-419.

6. Boeckstyns ME, Herzberg G, Sørensen AI, Axelsson P, Krøner K, Liverneaux PA, Obert L, Merser S. Can total wrist arthroplasty be an option in the treatment of the severely destroyed posttraumatic wrist? J Wrist Surg. 2013;2:324-329.

7. Cavaliere CM, Chung KC. A systematic review of total wrist arthroplasty compared with total wrist arthrodesis for rheumatoid arthritis. Plast Reconstr Surg. 2008;122:813-825.

8. Cavaliere CM, Chung KC. A cost-utility analysis of nonsurgical management, total wrist arthroplasty, and total wrist arthrodesis in rheumatoid arthritis. J Hand Surg Am. 2010;35:379-391.e2.

9. Cooney W, Manuel J, Froelich J, Rizzo M. Total wrist replacement: a retrospective comparative study. J Wrist Surg. 2012;1:165-172.

10. Ferreres A, Lluch A, Del Valle M. Universal total wrist arthroplasty: midterm follow-up study. J Hand Surg Am. 2011;36:967-973.

11. Goodman MJ, Millender LH, Nalebuff ED, Phillips CA. Arthroplasty of the rheumatoid wrist with silicone rubber: an early evaluation. J Hand Surg Am. 1980;5:114-121.

12. Grawe B, Heincelman C, Stern P. Functional results of the Darrach procedure: a long-term outcome study. J Hand Surg Am. 2012;37:2475-2480.e1-2.

13. Grosland NM, Rogge RD, Adams BD. Influence of articular geometry on prosthetic wrist stability. Clin Orthop Relat Res. 2004;421:134-142.

14. Gupta A. Total wrist arthroplasty. Am J Orthop (Belle Mead NJ). 2008;37(8 suppl 1):12-16.

15. Halim A, Weiss AC. Total wrist arthroplasty. J Hand Surg Am. 2017;42:198-209.
16. Integra LifeSciences Corporation. Integra ${ }^{\mathrm{TM}}$ Universal 2 - Total Wrist Fusion System. Available at: http://www.integralife.com/ products $\% 2 F p d f$ \% $\%$ Funiversal2 total wrist fusion system instructions for use.pdf. Accessed May 23, 2017.

17. Kistler U, Weiss AP, Simmen BR, Herren DB. Long-term results of silicone wrist arthroplasty in patients with rheumatoid arthritis. J Hand Surg Am. 2005;30:1282-1287.

18. Kobus RJ, Turner RH. Wrist arthrodesis for treatment of rheumatoid arthritis. J Hand Surg Am. 1990;15:541-546.

19. Menon J. Universal total wrist implant: experience with a carpal component fixed with three screws. J Arthroplasty. 1998;13:515523.

20. Morapudi SP, Marlow WJ, Withers D, Ralte P, Gabr A, Waseem M. Total wrist arthroplasty using the Universal 2 prosthesis. $J$ Orthop Surg (Hong Kong). 2012;20:365-368.

21. Sagerfors M, Gupta A, Brus O, Pettersson K. Total wrist arthroplasty: a single-center study of 219 cases with 5-year follow-up. J Hand Surg Am. 2015;40:2380-2387.

22. Shepherd DE, Johnstone A. A new design concept for wrist arthroplasty. Proc Inst Mech Eng H. 2005;219:43-52.

23. Weiss AC, Wiedeman G Jr, Quenzer D, Hanington KR, Hastings $\mathrm{H}$ 2nd, Strickland JW. Upper extremity function after wrist arthrodesis. J Hand Surg Am. 1995;20:813-817.

24. Weiss AP, Kamal RN, Shultz P. Total wrist arthroplasty. $J$ Am Acad Orthop Surg. 2013;21:140-148.

25. van Winterswijk PJ, Bakx PA. Promising clinical results of the universal total wrist prosthesis in rheumatoid arthritis. Open Orthop J. 2010;4:67-70.

26. Wollstein R, Carlson L. A minimal wrist arthroplasty for early wrist osteoarthritis. J Wrist Surg. 2013;2:176-179.

27. Yeoh D, Tourret L. Total wrist arthroplasty: a systematic review of the evidence from the last 5 years. J Hand Surg Eur Vol. 2015;40:458-468. 